Images in...

\title{
Isolated bilateral upper lobar anomalous pulmonary venous connection - a rare anomaly confirmed on CT imaging
}

\author{
Manoj Kumar Gupta, ${ }^{1}$ Ranjan Shetty, ${ }_{1}^{1}$ Nikhil Pande, ${ }^{2}$ Poonam Shenoy ${ }^{3}$
}

${ }^{1}$ Cardiology Department, Kasturba Medical College, Manipal, Karnataka, India; ${ }^{2}$ Medicine Department, Kasturba Medical College, Manipal, Karnataka, India;

${ }^{3}$ Radiology Department, Kasturba Medical College, Manipal, Karnataka, India

Correspondence to Dr Manoj Kumar Gupta,mk_jaiswal17@rediffmail.com

\section{DESCRIPTION}

We are reporting a case of a 5-year-old asymptomatic boy who had grade 3 ejection systolic murmur in pulmonary area on cardiac examination. $2 \mathrm{D}$ echocardiography showed dilated right atrium (RA) and right ventricle (RV) suggesting increased pulmonary to systemic flow. Suprasternal echocardiographic view raised doubt of vertical vein. There was no visible atrial septic defect (ASD) or significant pulmonary arterial hypertension. Partial anomalous pulmonary venous connection (PAPVC) was suspected without an associated ASD. This pulmonary venous anomaly is extremely rare and difficult to diagnose. Clinically, PAPVC is often asymptomatic and tends to go unnoticed until adulthood, and usually diagnosed during investigation of another illness. ${ }^{1}$ Left untreated, long-standing PAPVC predisposes the patient to right-sided volume overload, tricuspid regurgitation, arrhythmias, pulmonary hypertension, irreversible pulmonary vascular disease, right ventricular dysfunction/ failure. The development of symptoms and complications from PAPVC depends on the shunt fraction and thus on the number of pulmonary veins anomalously draining to the right heart. Surgical repair is warranted in cases of significant left to right shunt. In earlier times, catheter-based angiography was the imaging modality of choice in such cases. Nowadays, this has been superseded by echocardiography, CT angiography and MRI. Trans-

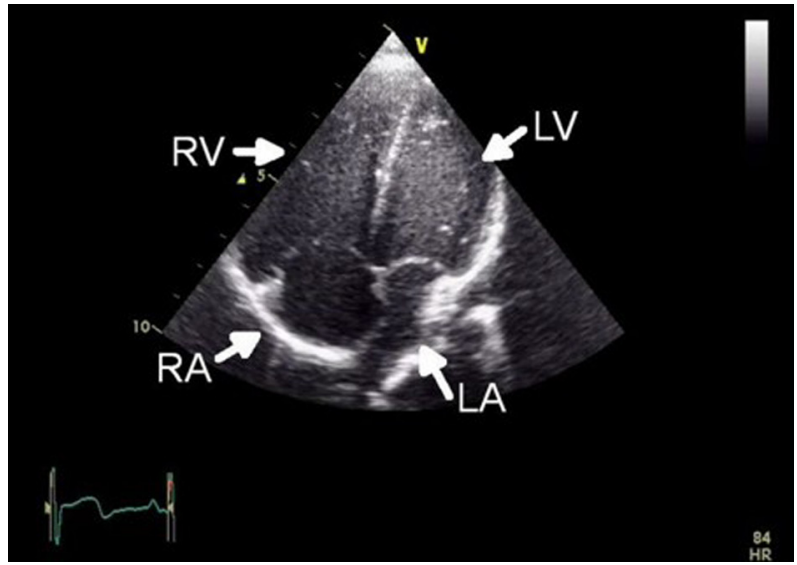

Figure 1 Transthoracic 2D echocardiography arrows showing dilated right atrium (RA), right ventricle (RV) and normal left atrium (LA), left ventricle (LV). oesophageal echocardiography (TEE) is able to image all four pulmonary veins in most of the cases, is not a good option in small children, being an invasive procedure necessitating general anaesthesia (GA). CT/MRI scans are reliable non-invasive modalities and avoids GA required for doing a conventional angiogram/TEE in children. ${ }^{2} 3$ These imaging techniques help in correct diagnosis and play an important role in proper preoperative planning before surgery. Cardiac MRI is useful for the diagnosis of congenital heart diseases as it provides both anatomical and physiological data far superior than CT and avoids unnecessary radiation. ${ }^{2}$ Lesser availability and cost are major limitations for the use of MRI in our centre as in other developing countries. In our case, we used CT imaging because of the same reason. Our patient had a very rare type of pulmonary venous connection which was suspected after seeing RA and RV dilatation on 2D echocardiography (figure 1) and isolated upper lobar pulmonary segmental hypervascularity on chest roentgenogram, (figure 2) cause of which was confirmed by CT angiographic imaging (figures 3 and 4). Though, there is a case report mentioning isolated left pulmonary veins draining in to vertical vein diagnosed by

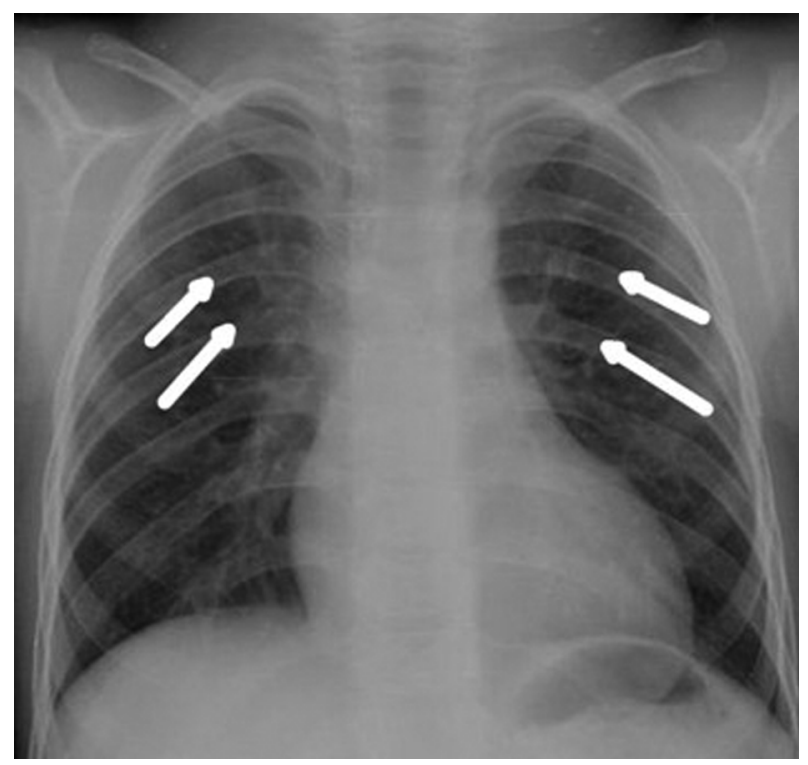

Figure 2 Chest x-ray arrows showing segmental hypervascularity. 


\section{BMJ Case Reports}

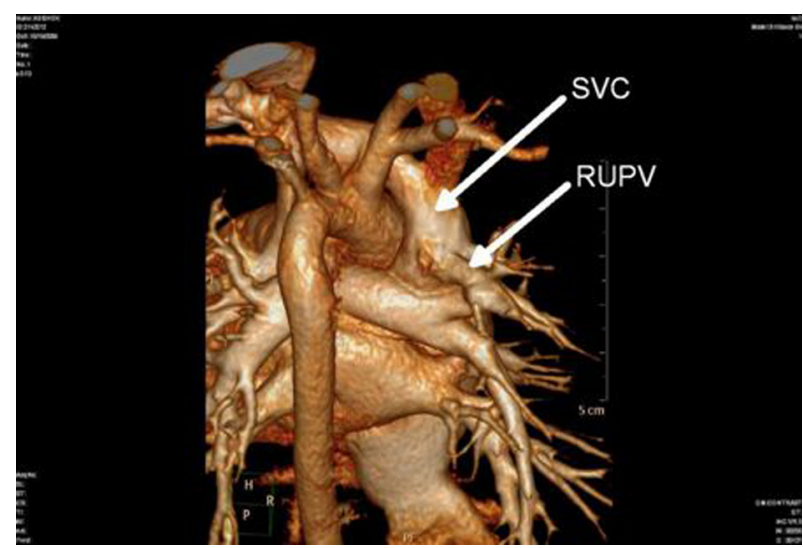

Figure 3 CT three dimensional imaging showing right upper pulmonary vein (RUPV) draining into right superior vena cava (SVC).

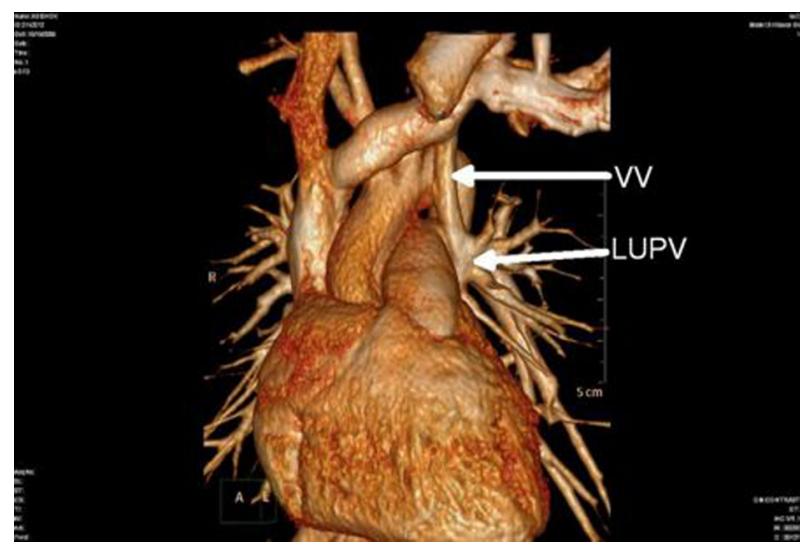

Figure 4 CT three dimensional imaging showing left upper pulmonary vein (LUPV) draining into vertical vein (VV). cardiac CT, ${ }^{4}$ our case is unique in having isolated bilateral upper lobar anomalous pulmonary venous connection and normal drainage of both lower lobe pulmonary veins to left atrium. In this case, cardiac CT imaging clearly delineated the pulmonary venous anatomy further substantiating the role of non-invasive modalities. The patient was recommended surgical correction and wanted to come back at a later date for the same.

\section{Learning points}

- Bilateral upper lobar PAPVC without ASD is an extremely rare congenital anomaly.

- Diagnosis can be easily missed and a high index of suspicion is warranted especially in cases with zonal hypervascularity on chest x-ray or unexplained RA-RV dilatation on echocardiography.

- CT/MRI imaging in these cases can be of paramount help in diagnosis and in proper surgical planning.

Acknowledgements Dr G Vivek, Assistant Professor, Department of Cardiology, KMC Manipal.

\section{Competing interests None.}

Patient consent Obtained.

\section{REFERENCES}

1. Javangula K, Cole J, Cross $\mathbf{M}$, et al. An unusual manifestation of left partial anomalous pulmonary venous connection. Interact Cardiovasc Thorac Surg 2010;11:846-7.

2. Ho ML, Bhalla $S$, Bierhals $A$, et al. MDCT of partial anomalous pulmonary venous return (PAPVR) in adults. J Thorac Imaging 2009;24:89-95

3. Wang ZJ, Reddy GP, Gotway MB, et al. Cardiovascular shunts: MR imaging evaluation. Radiographics 2003;23:S181-94.

4. Providência R, Botelho A, Mota P, et al. Multidetector CT of rare isolated partial anomalous pulmonary venous return. BMJ Case Rep 2011;doi:10.1136/ bcr.10.2010.3381

This pdf has been created automatically from the final edited text and images.

Copyright 2012 BMJ Publishing Group. All rights reserved. For permission to reuse any of this content visit http://group.bmj.com/group/rights-licensing/permissions.

BMJ Case Report Fellows may re-use this article for personal use and teaching without any further permission.

Please cite this article as follows (you will need to access the article online to obtain the date of publication).

Gupta MK, Shetty R, Pande N, Shenoy P. Isolated bilateral upper lobar anomalous pulmonary venous connection - a rare anomaly confirmed on CT imaging BMJ Case Reports 2012;10.1136/bcr.11.2011.5112, Published XXX

Become a Fellow of BMJ Case Reports today and you can:

- Submit as many cases as you like

- Enjoy fast sympathetic peer review and rapid publication of accepted articles

- Access all the published articles

- Re-use any of the published material for personal use and teaching without further permission

For information on Institutional Fellowships contact consortiasales@bmjgroup.com

Visit casereports.bmj.com for more articles like this and to become a Fellow

Keep up to date with all published cases by signing up for an alert (all we need is your email address) http://casereports.bmj.com/cgi/alerts/etoc 